\title{
Design and Simulation of MEMS Moisture Sensor Using COMSOL Multiphysics Software
}

\author{
Muhamad Nazrin Ismail ${ }^{1}$, Noriah Yusoff ${ }^{2} *$, Nor Hayati Saad ${ }^{3}$, Amirul Abd Rashid ${ }^{4}$ \\ ${ }^{1234}$ Faculty of Mechanical Engineering, Universiti Teknologi MARA, 40450 Shah Alam \\ *Corresponding author E-mail: noriahyusoff@salam.uitm.edu.my
}

\begin{abstract}
Micro-electro-mechanical system (MEMS) is a hybrid technology that combines electronic, electric and mechanical technology in a micron-size system. This allowed for higher performance and multifunction devices fabricated at much lighter weight and cost effective. One of the major application of MEMS is in sensor devices area. This paper highlight the simulation study of a typical moisture sensor fabricated from Tungsten Interdigitated (IDE) MEMS device. Using COMSOL Multiphysics software, the moisture sen sor was modelled based on the current material and physical dimension and layout. The model then go through validation proses to its sensitivity performance against the experimental result. Subsequently, the optimization on sensor sensitivity was carried out by varying the model parameters including the sensor physical dimension, working temperature and humidity. The simulation result suggest that the sensor sensitivity is highly correlated to the electrode distance value. The average sensitivity of the sensor improved to $48 \%$ better when the distance between reduced to $50 \%$ from 6 micron to 3 micron tested at temperature between $25^{\circ} \mathrm{C}$ to $45^{\circ} \mathrm{C}$. This information is valuable as the input to the sensor designer in finalizing the MEMS physical layout in producing highly sensitive moisture sensor devices.
\end{abstract}

Keywords: COMSOL; MEMS; moisture sensor; capacitance; interdigitated device.

\section{Introduction}

The electronics industry have gone through huge advancement beyond the More's law prediction. One of the significant breakthrough was in MEMS technology where it convert any physical changes, events and parameters to mechanical, electrical and optical signals and vice versa. The advantage of integrating multiple function of system in smaller footprint has enabled the production of smaller, lightweight and low consumption devices. The application of MEMS can be found in every modern gadget of human lifestyles including computer, telecommunications, automotive and transportations, healthcare and others. The architecture and operating principle of MEMS is by utilizing micro scale features of electromechanical, electronics, optical and biological components however still required optimization in their design, analysis and fabrication [1].

The main components in MEMS consists of microsensor, microactuator, microelectronics and microstructure (refer to Fig.1). Microsensors is consider as the input for MEMS system where it is used to detect any changes in the system's environment by measure the thermal, mechanical, magnetic, chemical or electromagnetic, information of phenomena. The information measured by the sensor will be processed by microelectronic and send the signal to the microactuator to create form of changes to the environments [2].

\subsection{Interdigitated (IDE) Sensor}

Interdigitated sensor follows the rule of two parallel plate capacitor, where one side of both of the electrodes will be facing up for the material under test [4]. Fig. 2 shows the electric field line of the parallel plate capacitor and an interdigital sensor. The electrical field lines generated by the sensor will penetrate into the material under test and the impedance of the sensor will be changed. Interdigital sensor behaves as capacitor in which the capacitive reactance becomes the function of the system properties and the system properties can be evaluated. AC voltage source will be applied between positive terminal and negative terminal as an excitation voltage. The electric field is created and it penetrates from positive terminal to negative terminal as can be seen in Fig. 2 .

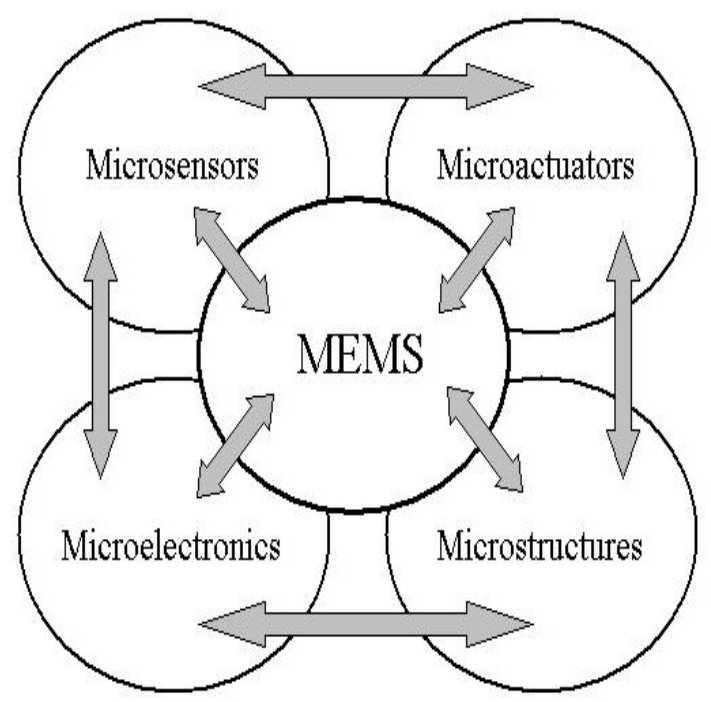

Fig. 1: A schematic illustration of MEMS components and their interdependence [3] 


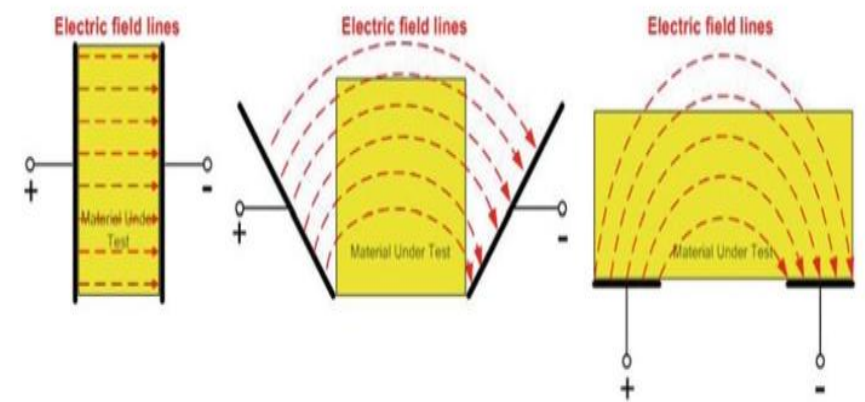

Fig. 2: Electric field lines of parallel plate capacitor and on coplanar interdigital sensors [4]

The configuration of the interdigital electrodes can be repeated many times in order to get a stronger signal. Since the repeated configuration parallel in-plane electrodes look like a digit-like or finger-like thus, the term "interdigital" is used. Fig. 3 shows a typical conventional interdigital electrodes sensor platform.

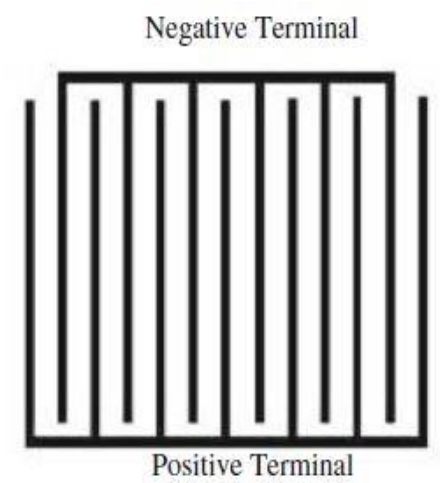

Fig. 3: Configuration of conventional planar interdigital sensor [4]

The distance between the two consecutive electrodes of the same polarity influenced the depth penetration of the electric field or also known as the fringing fields. Fig. 4 shows the side view of interdigital sensor and the penetration of the electric field. Also Fig. 4 exhibits the pitch length $\left(l_{l}, l_{2}, l_{3}\right)$ with different depth of penetration. Research by [4] reported that when the electric field depth penetration of the electric field is increased, the strength of the electric field is weakened. Theoretically, the fringing electric field is weakening as the distance between the electrodes is increasing.

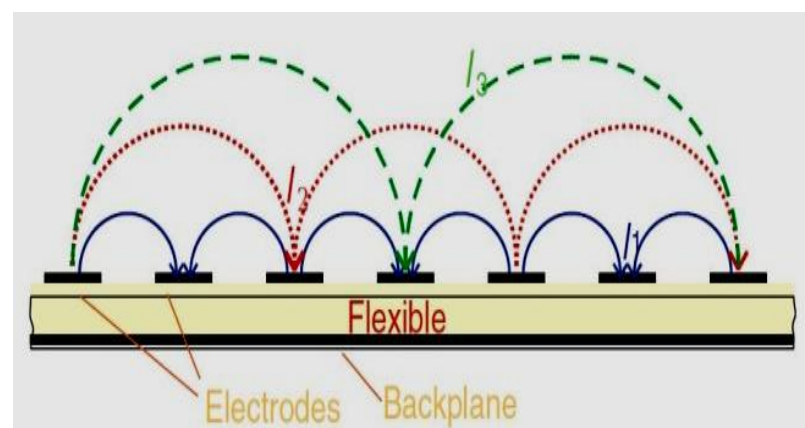

Fig. 4: Electric field formed between positive and negative electrodes for different pitch length $\left(l_{1}, l_{2}, l_{3}\right)[4]$

\section{Method}

In this research, the framework of the overall activities conducted in this study is described in Fig.5. The simulation model is validated by comparing the simulation results against the experimental data obtained from the previous study in [5].

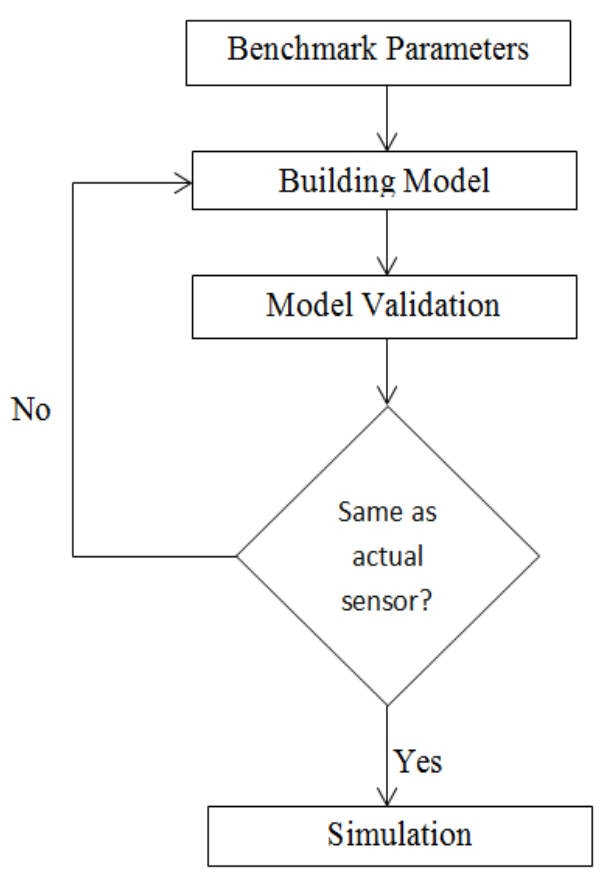

Fig. 5 Methodology Flow Chart

\subsection{Benchmark Parameter}

The benchmark parameter setting is according to the actual parameters of the moisture sensor of the research in [5]. This benchmark parameters is used as the model building setting of the moisture sensor using COMSOL Multiphysics software. The parameters include the size, the material used and also other model building input that are required for the moisture sensor modelling process.

\subsection{Building Model}

The simulation model is constructed according to the benchmark parameters; refer to Fig. 8. The model was built by using COMSOL Multiphysics software according to the dimension and the boundary conditions that were set for the moisture sensor accordingly.

\subsection{Validation}

The simulation results; the capacitance reading is compared against the experimental results obtained in research [5] hence the validated the MEMS moisture sensor that was built in COMSOL Multiphysics software. The validation process is prerequisite in simulation studies because the constructed model must be representing the actual condition of the subject matter in order to get a reliable simulation output result. Then, the validated model is used a reference model. Thus, any changes made on the investigated parameters were compared and analyzed accordingly.

\subsection{Improvisation}

In improvisation process, the parameters of the validated model (reference model) were changed in terms of the size of the electrodes and the distance between the electrodes in order to optimize the performance of the sensor which is the sensitivity of the capacitance value. The simulation results of the improvised model were compared against the reference model and the performance of both conditions were analyzed. 


\section{MEMS Moisture Sensor Modelling}

Fig. 6 shows the MEMS moisture sensor that was built in COMSOL Multiphysics software. The MEMS moisture sensor has 126 fingers pair with equidistance of each pair. The electrodes is made of Tungsten and its material properties is set according to Table 1. The first layer under the electrodes is the silicon dioxide and the bottom layer is silicon substrate. In this study, the model is built according to a pair of the electrodes that consists of a terminal electrode and a ground electrode respectively.

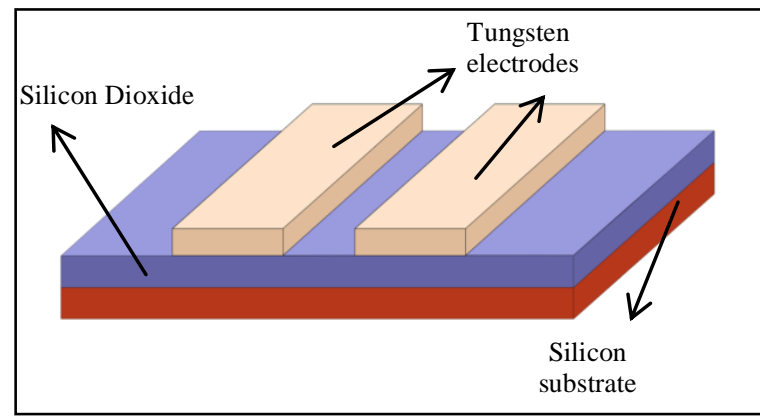

Fig. 6: Schematic Diagram of the MEMS Moisture Sensor

Table 1: Material properties of Tungsten

\begin{tabular}{|l|l|l|}
\hline Property & Value & Unit \\
\hline Relative Permittvity & 30 & 1 \\
\hline Electrical Conductivity & $2.00 \mathrm{E}+07$ & $\mathrm{~S} / \mathrm{m}$ \\
\hline Coefficient of Thermal Expansion & $4.50 \mathrm{E}-06$ & $1 / \mathrm{K}$ \\
\hline Heat Capacity at contacnt pressure & 132 & $\mathrm{~J} /(\mathrm{kg} . \mathrm{K})$ \\
\hline Density & 19350 & $\mathrm{~kg} / \mathrm{m}^{3}$ \\
\hline Thermal Conductivity & 174 & $\mathrm{~W} /(\mathrm{m} . \mathrm{K})$ \\
\hline Young's modulus & $4.11 \mathrm{E}+11$ & $\mathrm{~Pa}$ \\
\hline Poisson's ratio & 0.28 & 1 \\
\hline
\end{tabular}

Fig.7 represent the initial model drawing using COMSOL Software. Detail dimensional of the MEMS moisture sensor model is illustrated in Fig. 8.

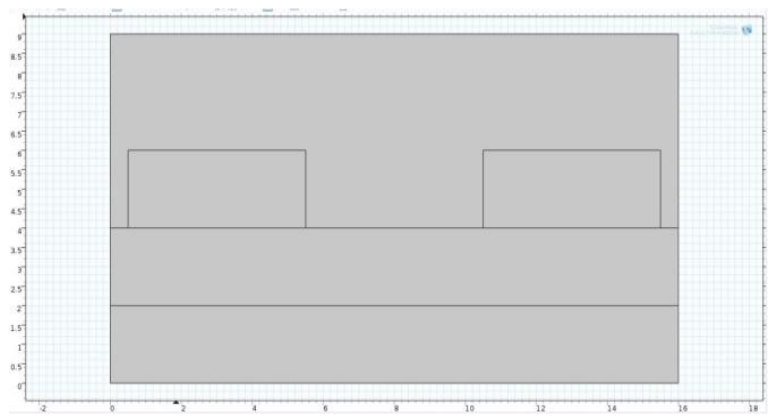

Fig. 7: Model drawing in the COMSOL Multiphysics Software

Fig. 8 shows the MEMS moisture sensor model that was extruded with $5 \mu \mathrm{m}$ length. A thin silicon dioxide was deposited in order to give a capacitive properties of the structure while the silicon at the bottom layer was used as the substrate in the structure. After the material selection for modelling the structure was done, the boundary condition was set accordingly by selecting the appropriate physics setup. The physics setup in the COMSOL Multiphysics software that was employed for this study were "Electro-mechanics" and "Heat Transfer in Fluid". The electromechanics physic is used for modelling the boundary condition for the terminal and ground electrodes surface. The voltage of the terminal electrode was set at 1 Volt. The modelling of the boundary condition of the heat transfer in fluid physic is representing the surrounding air domain condition, where the humidity and the temperature were set accordingly.

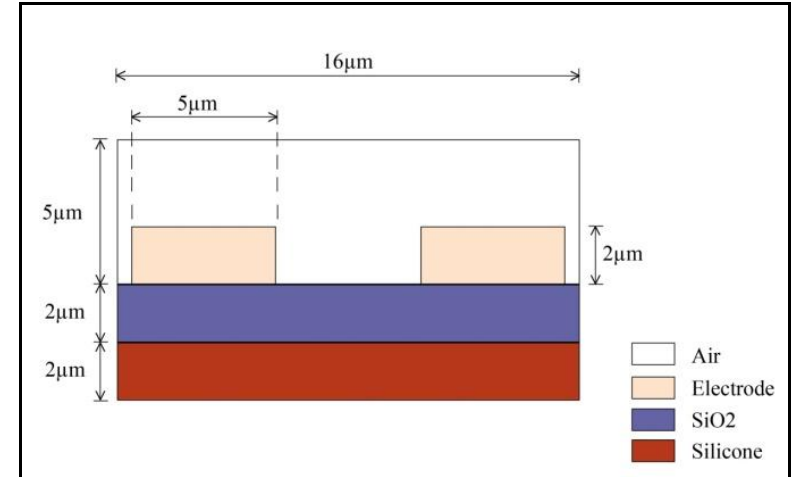

Fig. 8: Cross section dimension of the model in COMSOL Multiphysics

\section{Result and Discussion}

The reference model is obtained from the validation model. The validation process was done by comparing the simulation results of the constructed MEMS moisture sensor via COMSOL Multiphysics software against the actual experimental results in [5]. The percentage of error between the simulation and experimental results should be less than $10 \%[6,7]$. Noriah Yusoff et al and Rosli Darmawan et al asserted that if the simulation result of the reference model is less than $10 \%$ as compared against the actual result then the model can be validated and accepted as a reference model $[6,7]$. Table 2 shows the percentage of error between the capacitance value of the experimental study and capacitance value of the simulation model. The percentage of errors were calculated according to the various temperature and $\mathrm{RH}$ setting. The overall percentage of errors obtained were less than $10 \%$. Therefore, the constructed MEMS moisture sensor simulation is validated and can be accepted as a reference model. The simulation model was validated against the experimental model with $4.39 \%$ error; less than $10 \%$ as suggested by [6].

Table2: Percentage of error between the simulation and experimental study of the capacitance value; Reference Model.

\begin{tabular}{|c|c|c|c|c|c|}
\hline $\begin{array}{l}\text { Temp. } \\
\left({ }^{\circ} \mathrm{C}\right)\end{array}$ & \begin{tabular}{|l|} 
Relative \\
Humidity \\
$($ RH) $(\%)$
\end{tabular} & $\begin{array}{l}\text { Capacitance } \\
\text { in Previous } \\
\text { Study (pF) }\end{array}$ & $\begin{array}{l}\text { Capacitance } \\
\text { from the } \\
\text { simulation } \\
(\mathrm{pF})\end{array}$ & $\begin{array}{l}\text { Error } \\
(\%)\end{array}$ & $\begin{array}{l}\text { Sensitivity, } \\
\text { S } \\
\text { pF/(\% RH) }\end{array}$ \\
\hline \multirow{3}{*}{25} & 50.00 & 190.85 & 186.00 & $2.54 \%$ & \multirow{3}{*}{3.70} \\
\hline & 70.00 & 280.42 & 260.00 & $7.28 \%$ & \\
\hline & 90.00 & 320.43 & 334.00 & $4.23 \%$ & \\
\hline \multirow{3}{*}{35} & 50.00 & 192.03 & 192.00 & $0.02 \%$ & \multirow{3}{*}{3.83} \\
\hline & 70.00 & 280.25 & 269.00 & $4.01 \%$ & \\
\hline & 90.00 & 320.53 & 345.00 & $7.63 \%$ & \\
\hline \multirow{3}{*}{45} & 50.00 & 191.84 & 198.00 & $3.21 \%$ & \multirow{3}{*}{3.98} \\
\hline & 70.00 & 279.89 & 277.00 & $1.03 \%$ & \\
\hline & 90.00 & 325.77 & 357.00 & $9.59 \%$ & \\
\hline \multicolumn{5}{|c|}{ Average sensitivity } & 3.84 \\
\hline
\end{tabular}

From Table 2, the sensitivity of the sensor was defined as the change in output of the sensor per unit change [8]. Equation (1) shows the equation that been used to calculate the sensitivity of the sensor [9].

Sensitivity, $S=\frac{C_{H 2}-C_{H 1}}{H_{2}-H_{1}}$

Where,

$C_{H} \quad=$ Capacitance Value at the humidity of $\mathrm{H}$

$H \quad$ = Humidity

As an example; from Table 2 in green shading at the $\mathrm{RH}$ range of $\mathrm{H}_{2}$ and $\mathrm{H}_{1}$ is in between RH90 and RH50, the range value of capacitance is in between 186 and 334. The average sensitivity of the reference model $25^{\circ} \mathrm{C}$ temperature, different humidity was 3.83 $\mathrm{pF} /$ ( $\%$ of humidity). Correspondingly, the average sensitivity of 
the sensor in the group of the same humidity with different temperature setting was $0.87 \mathrm{pF} /{ }^{\circ} \mathrm{C}$.

The validated model was then used to further explore the sensor performance and eventually the optimize design parameters were established. In this study two main parameters were investigated, the width of the electrode and the gap between electrodes; A and B respectively (refer to Fig.9). Then the simulation results based on the output capacitance value were evaluated accordingly. Fig. 9 is the constructed according to the reference model except for electrode's width and gap between the electrodes are labelled as A and $\mathrm{B}$ respectively.

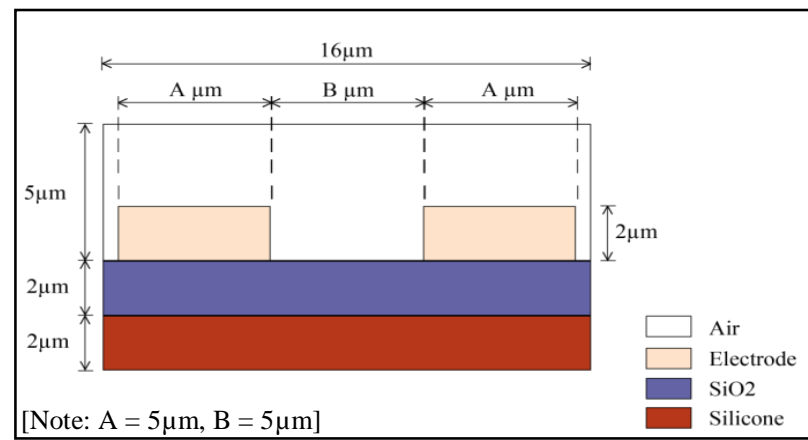

Fig. 9: Dimension of the improvised MEMS moisture sensor model.

The first modification was made by reducing the gap between electrodes to $3 \mu \mathrm{m}(\mathrm{B}=3 \mu \mathrm{m})$ while maintaining the electrode width, $\mathrm{A}$ at $5 \mu \mathrm{m}$. Table B displays the simulation results of the first modification done.

Table 3: Capacitance value when the width of the electrode (A) is $3 \mu \mathrm{m}$

\begin{tabular}{|c|c|c|c|c|}
\hline \multirow[b]{2}{*}{$\begin{array}{l}\text { Temp } \\
\left({ }^{\circ} \mathbf{C}\right)\end{array}$} & \multirow[b]{2}{*}{$\begin{array}{c}\text { Relative } \\
\text { Humidity } \\
(\%)\end{array}$} & \multicolumn{2}{|c|}{ Capacitance Value (pF) } & \multirow{2}{*}{$\begin{array}{c}\text { Sensitivity } \\
\text { S } \\
(\text { pF/\% RH })\end{array}$} \\
\hline & & $\begin{array}{c}\text { Reference } \\
\text { Model (pF) }\end{array}$ & $\begin{array}{c}\text { Improvised Model } \\
\text { (Simulation result) } \\
(\mathrm{pF})\end{array}$ & \\
\hline \multirow{3}{*}{25} & 50 & 186.00 & 200.00 & \multirow{3}{*}{4.00} \\
\hline & 70 & 260.00 & 280.00 & \\
\hline & 90 & 334.00 & 360.00 & \\
\hline \multirow{3}{*}{35} & 50 & 192.00 & 207.00 & \multirow{3}{*}{4.13} \\
\hline & 70 & 269.00 & 289.00 & \\
\hline & 90 & 345.00 & 372.00 & \\
\hline \multirow{3}{*}{45} & 50 & 198.00 & 213.00 & \multirow{3}{*}{4.28} \\
\hline & 70 & 277.00 & 299.00 & \\
\hline & 90 & 357.00 & 384.00 & \\
\hline \multicolumn{4}{|r|}{ Average Sensitivity } & 4.14 \\
\hline
\end{tabular}

Table 3 exhibits the capacitance value of the improvised design with $3 \mu \mathrm{m}$ width of every IDE fingers. The sensitivity calculated and presented in Table 3 . The average sensitive is of the improvised Model 1 is $4.14 \mathrm{pF} / \% \mathrm{RH}$ and $0.93 \mathrm{pF} /{ }^{\circ} \mathrm{C}$.

The second modification was done by changing the electrode width, A to $6 \mu \mathrm{m}$ and maintaining the gap, B at $5 \mu \mathrm{m}$. The result of the second modification is presented in Table 4 . The average sensitive of the improvised Model 2 is $4.15 \mathrm{pF} / \% \mathrm{RH}$ and $0.93 \mathrm{pF} /{ }^{\circ} \mathrm{C}$.

Table 4: Capacitance value when the distance between the electrodes (B) is $6 \mu \mathrm{m}$

\begin{tabular}{|c|c|c|c|c|}
\hline \multirow[b]{2}{*}{$\begin{array}{c}\text { Temp } \\
\left({ }^{\circ} \mathrm{C}\right)\end{array}$} & \multirow[b]{2}{*}{$\begin{array}{c}\text { Relative } \\
\text { Humidity } \\
(\%)\end{array}$} & \multicolumn{2}{|c|}{ Capacitance Value (pF) } & \multirow[b]{2}{*}{$\begin{array}{c}\text { Sensitivity, } \mathbf{S} \\
\text { pF/(\% RH })\end{array}$} \\
\hline & & $\begin{array}{c}\text { Reference } \\
\text { Model } \\
\text { (pF) }\end{array}$ & $\begin{array}{c}\text { Improvised Model } \\
\text { (Simulation result) } \\
(\mathrm{pF})\end{array}$ & \\
\hline \multirow{3}{*}{25} & 50 & 186.00 & 200 & \multirow{3}{*}{4.03} \\
\hline & 70 & 260.00 & 281 & \\
\hline & 90 & 334.00 & 361 & \\
\hline \multirow{3}{*}{35} & 50 & 192.00 & 207 & \multirow{3}{*}{4.15} \\
\hline & 70 & 269.00 & 290 & \\
\hline & 90 & 345.00 & 373 & \\
\hline \multirow{3}{*}{45} & 50 & 198.00 & 214 & \multirow{3}{*}{4.28} \\
\hline & 70 & 277.00 & 299 & \\
\hline & 90 & 357.00 & 385 & \\
\hline & & & Average Sensitivity & 4.15 \\
\hline
\end{tabular}

The third modification of the model was made by changing the electrode width A to $6 \mu \mathrm{m}$ while the gap B is maintained at $5 \mu \mathrm{m}$; similar to the reference model. The result of the third modification is presented in Table 5. The average sensor sensitivity of the improvised Model 3 is $4.15 \mathrm{pF} / \% \mathrm{RH}$ and $0.95 \mathrm{pF} /{ }^{\circ} \mathrm{C}$.

Table 5: Capacitance value when the width of the electrode (A) is $6 \mu \mathrm{m}$

\begin{tabular}{|c|c|c|c|c|}
\hline \multirow[b]{2}{*}{$\begin{array}{c}\text { Temp } \\
\left({ }^{\circ} \mathbf{C}\right)\end{array}$} & \multirow[b]{2}{*}{$\begin{array}{c}\text { Relative } \\
\text { Humidity } \\
\quad(\%)\end{array}$} & \multicolumn{2}{|c|}{ Capacitance Value (pF) } & \multirow{2}{*}{$\begin{array}{c}\text { Sensitivity, } \\
\text { S } \\
\text { (pF/\% RH) }\end{array}$} \\
\hline & & $\begin{array}{c}\text { Reference } \\
\text { Model } \\
(\mathbf{p F})\end{array}$ & $\begin{array}{c}\text { Improvised Model } \\
\text { (Simulation result) } \\
(\mathbf{p F})\end{array}$ & \\
\hline \multirow{3}{*}{25} & 50 & 186.00 & 201 & \multirow{3}{*}{4.03} \\
\hline & 70 & 260.00 & 282 & \\
\hline & 90 & 334.00 & 362 & \\
\hline \multirow{3}{*}{35} & 50 & 192.00 & 208 & \multirow{3}{*}{4.15} \\
\hline & 70 & 269.00 & 291 & \\
\hline & 90 & 345.00 & 374 & \\
\hline \multirow{3}{*}{45} & 50 & 198.00 & 215 & \multirow{3}{*}{4.28} \\
\hline & 70 & 277.00 & 301 & \\
\hline & 90 & 357.00 & 386 & \\
\hline & & & Average Sensitivity & 4.15 \\
\hline
\end{tabular}

The fourth modification was made by reducing the gap B to $3 \mu \mathrm{m}$ while the length $\mathrm{A}$ is maintained at $5 \mu \mathrm{m}$. The result of the fourth modification is presented in Table 6. The average sensor sensitivity of the improvised Model 4 is $6.12 \mathrm{pF} / \% \mathrm{RH}$ and $1.38 \mathrm{pF} /{ }^{\circ} \mathrm{C}$.

Table 6: Capacitance value when the distance between the electrodes is $3 \mu \mathrm{m}$

\begin{tabular}{|c|c|c|c|c|}
\hline \multirow[b]{2}{*}{$\begin{array}{c}\text { Temp } \\
\left({ }^{\circ} \mathrm{C}\right)\end{array}$} & \multirow[b]{2}{*}{$\begin{array}{c}\text { Relative } \\
\text { Humidity } \\
(\%)\end{array}$} & \multicolumn{2}{|c|}{ Capacitance Value $(\mathrm{pF})$} & \multirow[b]{2}{*}{$\begin{array}{l}\text { Sensitivity, } \\
\text { S } \\
\text { pF/(\% RH })\end{array}$} \\
\hline & & $\begin{array}{l}\text { Reference } \\
\text { Model } \\
\text { (pF) }\end{array}$ & $\begin{array}{c}\text { Improvised Model } \\
\text { (Simulation result) } \\
(\mathrm{pF})\end{array}$ & \\
\hline \multirow{3}{*}{25} & 50 & 186.00 & 295 & \multirow{3}{*}{5.93} \\
\hline & 70 & 260.00 & 414 & \\
\hline & 90 & 334.00 & 532 & \\
\hline \multirow{3}{*}{35} & 50 & 192.00 & 305 & \multirow{3}{*}{6.13} \\
\hline & 70 & 269.00 & 428 & \\
\hline & 90 & 345.00 & 550 & \\
\hline \multirow{3}{*}{45} & 50 & 198.00 & 315 & \multirow{3}{*}{6.33} \\
\hline & 70 & 277.00 & 441 & \\
\hline & 90 & 357.00 & 568 & \\
\hline \multicolumn{4}{|r|}{ Average Sensitivity } & 6.13 \\
\hline
\end{tabular}

Fig. 10 compares the capacitance values of the simulation results in Table 3; Model 1, Table 4; Model 2, Table 5; Model 3 and Table 6; Model 4 at $25^{\circ} \mathrm{C}$ against the reference model (Table 2). The graph trends show that the line capacitance value from Table 6; Model 4 achieved the highest capacitance value compared to the rest. Table 6 is the result from the improvised Model 4 where the gap between the electrodes was reduced from $5 \mu \mathrm{m}$ to $3 \mu \mathrm{m}$. When the gap between the electrodes is smaller, the capacitance value of the sensor is higher which because of the stronger electrical field between the electrodes. Results from Table 5 (Model 3) and Table 3 (Model 1), indicate the capacitance values that were generated from the improvised Model 3 and Model 1 are at par to each other; the width electrode (A) of $6 \mu \mathrm{m}$ and $3 \mu \mathrm{m}$. respectively This finding point out that changes in between the electrode gap is giving more impact rather than the electrode width.

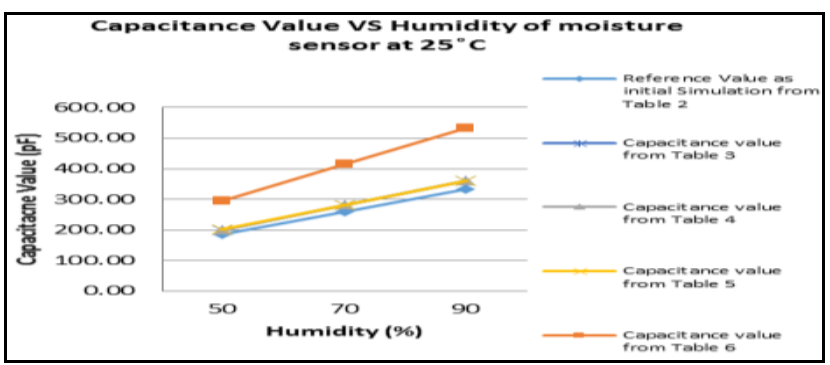

Fig. 10: Graph from the result of reference model and improvised model at $25^{0} \mathrm{C}$. 


\section{Conclusion}

The understudied moisture sensor was successfully simulated and validated using the COMSOL Multiphysics software. The simulation result shows that the sensor device is more sensitive to humidity rather than the temperature. This attribute is in agreement with the main objective of the moisture sensor development; highly sensitive to the moisture presence. The key findings from this research are, by reducing the electrodes' gap closer to each other, it helps to increase the sensitivity of the sensor. Also, changes in the electrode geometrical size does not give significant impact to the capacitance reading. These findings suggest that reducing the gaps in between the electrodes with the appropriate electrode width are the promising solutions in optimizing the sensor performance.

\section{Acknowledgement}

We would like to thank Research Management Institute of Universiti Teknologi MARA (UiTM) for fully funding this research project under the BESTARI Research Grant Scheme (600-IRMI/MyRA 5/3/BESTARI (012/2017)).

\section{References}

[1] S. E. Lyshevski, MEMS and NEMS: System, Device and Structures. CRC Press Published January 18, 2002.

[2] Introduction and M. January, Prime Faraday Technology Watch An Introduction to MEMS (Micro-electromechanical Systems) MEMS has been identified as one of the most promising technologies for PRIME Faraday Partnership, no. January. 2002.

[3] M. J. Madou, Fundamentals of Microfabrication: The Science of Miniaturization, Second Edition, no. Mar. CRC Press, 2002.A.V.

[4] Y. Alexander, V. Mamishev Kishore, Sundara-Rajan Fumin, Y. Du, And Z. Markus, "Interdigital Sensors and transducers," IEEE J. Proceeding, vol. 92, no. 5, p. 335, 2004.

[5] Noriah Yusoff et al., "Design Of Experiment Using Minitab For Screening Breath Sensor Workability Performance," J. Teknologi., vol. 11, no. 9, pp. 67-72, 2015.

[6] Noriah Yusoff, Design and Simulation for an Automated Production Line for Manufacturing Injected Polyurethane Car Seats, April 2008.

[7] Rosli Darmawan, Mohd. Rasid Osman, Rosmah Mohd Yusoff, Napsih Ismail, and Zulkiflie Leman, (2004). "Manufacturing Plant Performance Evaluation by Discrete Event Simulation.” Journal of Faculty Mechanical Engineering, Volume 1(Number 1), pp 1-14. 